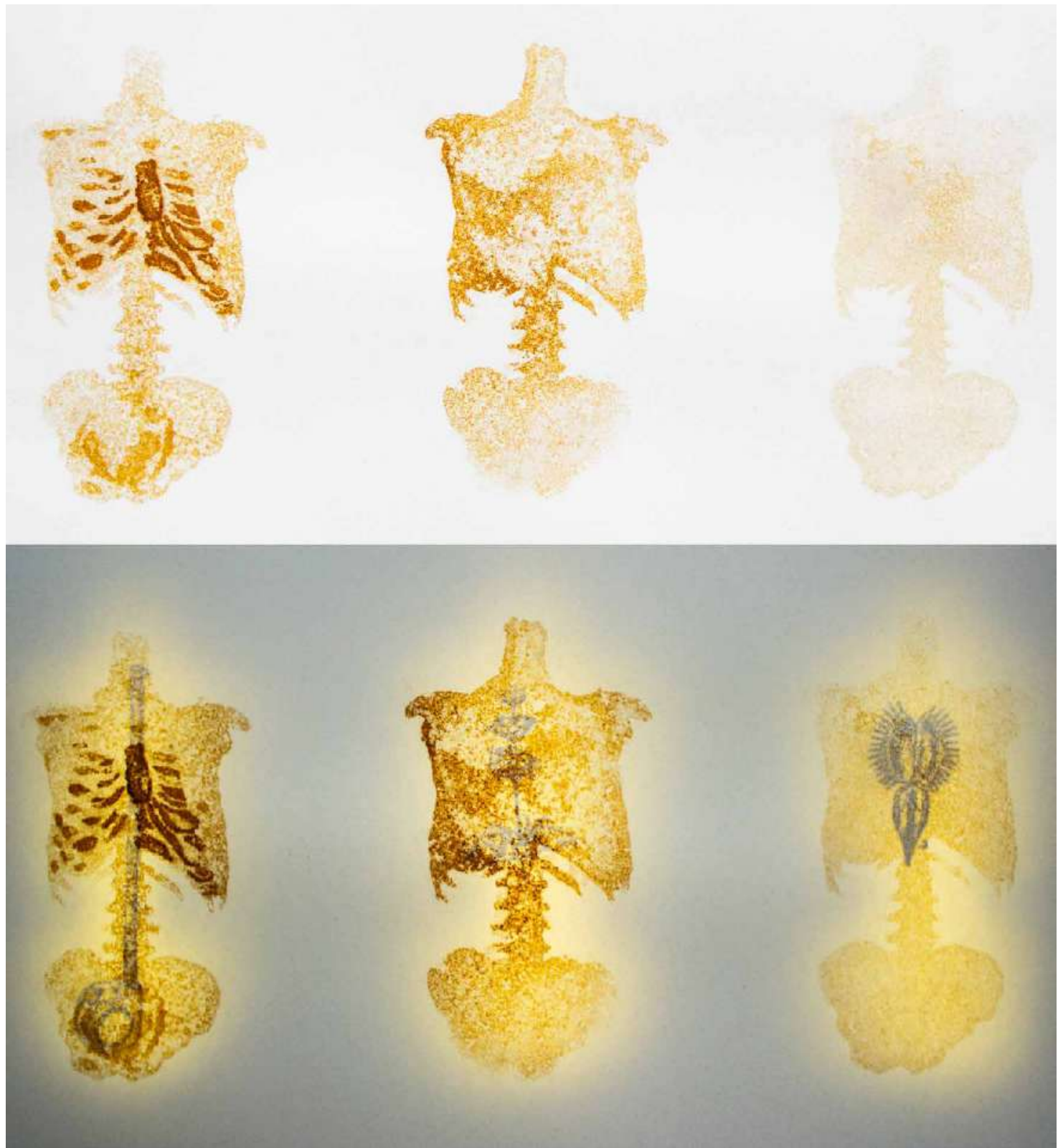

Yamith Quiroz David

Estudio 2

De la serie Herrumbres, cuerpos desechos

Dibujo con óxido ferroso, tinta, luz led cálida sobre papel Arches

$33,5 \times 43,5 \times 7 \mathrm{~cm}$

2020

Medellín 


\title{
El triunfo de las campañas posmodernas. Los casos de las alcaldías de Bogotá y Medellín en las elecciones de $2019 *$
}

\author{
Ismael Crespo Martínez (España)** \\ José Alejandro Cepeda Jiménez (Colombia)*** \\ José Miguel Rojo Martínez (España) ${ }^{* * * *}$
}

\section{Resumen}

En este artículo se analiza la presencia de los rasgos propios de las campañas posmodernas en las elecciones para las alcaldías de Bogotá y Medellín en 2019, y qué aprendizaje cabe extraer de todo ello. Las exitosas campañas de Claudia López y de Daniel Quintero pueden considerarse casos relevantes para explicar las transformaciones que está viviendo la comunicación político-electoral. Ambos candidatos, ajenos a las estructuras tradicionales de los partidos, diseñaron campañas de tipo posmoderno en las que primaron los temas posmaterialistas, como el ecologismo y el feminismo, al mismo tiempo que construyeron potentes relatos personales. Los nuevos valores emergentes, especialmente significativos para el público joven, la importancia de la personalización y el uso de técnicas comunicativas innovadoras se pusieron de manifiesto en la estrategia de estos candidatos.

\section{Palabras clave}

Comportamiento Político; Campañas Electorales; Comunicación Política; Personalismo Político; Elecciones Locales; Colombia.

Fecha de recepción: febrero de 2020

- $\quad$ Fecha de aprobación: agosto de 2020

\footnotetext{
* Este artículo se enmarca en el contrato de investigación realizado en 2019 entre la Universidad de Murcia y el Instituto Coordenadas de Gobernanza y Economía Aplicada de Madrid, España, para la realización del estudio Liderazgo municipal.

** Politólogo. Doctor en Ciencias Políticas y Sociología. Director del Departamento de Ciencia Política, Antropología Social y Hacienda Pública, Universidad de Murcia, España. Correo electrónico: icrespo@um.es - Google Scholar: https://scholar.google.com/citations?hl=es\&user=FvMZX9wAAA AJ

*** Periodista y politólogo. Magíster en Análisis de Problemas Políticos, Económicos e Internacionales Contemporáneos. Doctor en Ciencias Políticas y de la Administración. Profesor en la Pontificia Universidad Javeriana de Bogotá. Correo electrónico: cepeda-j@javeriana.edu.co

**** Graduado en Ciencia Política y Gestión Pública. Magíster en Análisis Político Aplicado. Correo electrónico: josemiguel.rojo@um.es - Orcid: 0000-0001-9491-4839 - Google Scholar: https://scholar. google.com/citations?hl=es\&user=3sMJEYcAAAAJ
} 


\title{
Cómo citar este artículo
}

Crespo, Ismael; Cepeda, José Alejandro y Rojo, José Miguel. (2020). El triunfo de las campañas posmodernas. Los casos de las alcaldías de Bogotá y Medellín en las elecciones de 2019. Estudios Políticos (Universidad de Antioquia), 59, pp. 253-278. DOI: 10.17533/udea.espo.n59a11

\section{The Success of Post-Modern Campaigns. The Cases of Bogotá and Medellín's Mayors in the 2019 Elections}

\begin{abstract}
This article analyzes the presence of the characteristics of post-modern campaigns in the elections for Bogotá and Medellín mayors in 2019, and what lessons can be learned from these experiences. The successful campaigns of Claudia López and Daniel Quintero can be considered relevant cases to explain the transformations that political-electoral communication is undergoing. Both candidates, outside the traditional party structures, designed postmodern-type campaigns in which post-materialist issues —such as environmentalism and feminism- prevailed, while building powerful personal narratives. The new emerging values, especially significant for young audiences, the importance of personalisation and the use of innovative communication techniques were highlighted in the strategy of these candidates.
\end{abstract}

\section{Keywords}

Political Behavior; Electoral Campaigns; Political Communication; Political Personalism; Local Elections; Colombia. 
El triunfo de las campañas posmodernas. Los casos de las alcaldías de Bogotá y Medellín...

\section{Introducción}

Colombia ha atravesado múltiples transformaciones en su vida política a partir de la Constitución Política de 1991. Todas ellas conllevaron la afirmación de un nuevo pacto social, la compleja búsqueda de la paz y una apertura y reacomodamiento de su sistema de partidos. A dos décadas de corrido el siglo xxı procede hacer una doble consideración: a) se ha consolidado la ruptura del bipartidismo liberal-conservador que predominó en los ámbitos presidencial y legislativo hasta la Asamblea Nacional Constituyente de 1990 y sus ecos del Frente Nacional (1958-1974): y b) la incapacidad de institucionalizar por completo un sistema de partidos nuevo, a pesar de la reconcentración forzada por la Reforma Política de 2003, permaneciendo en la vieja categoría de «estado fluido» (Sartori, 1976). Esto es posible porque en medio del desprestigio partidista, el arribo del personalismo y de la nueva política Colombia ha prolongado la materialización de una nueva era de posconflicto en todo su territorio.

El comportamiento político en el ámbito subnacional ofrece una réplica del marco general: una intensa fragmentación representativa de los cargos uninominales en gobernaciones y alcaldías, incluso también en los plurinominales de asambleas y concejos. De ahí que se haya producido una emergencia de partidos pasajeros, grupos significativos de ciudadanos — candidaturas temporales respaldadas a través de firmas, opción creciente en Colombia para presentar figuras independientes (Consejo Nacional Electoral, 2019, enero 24)_, coaliciones y listas dispersas que luchan por lograr visibilidad mediática. El sistema de partidos colombiano, sin haber dejado sus rasgos clientelares, pero sin modernizar su vida partidista, se puede caracterizar como «pluripartidismo moderado» (Sartori, 1976). Su reto, mejorar la tarea de agregación de los intereses ciudadanos.

En las elecciones regionales del 27 de octubre de 2019 se pueden observar estas tendencias. Las campañas triunfantes de las principales ciudades de Colombia presentan un modelo de comunicación política posmoderna o de nueva política que ya no solo desafía la institucionalización de determinados cambios en el sistema de partidos, sino que parece desprenderse de él para girar en torno a una dinámica autónoma.

El presente artículo se propone describir dos campañas que han enfrentado discursos y estrategias novedosas versus discursos y estrategias tradicionales. Bogotá, la capital y segundo cargo público de importancia en Colombia, 
con su primera alcaldesa elegida, de talante progresista y representante de la diversidad sexual; y Medellín, centro político y económico de importancia vital del departamento de Antioquia, que eligió a un joven outsider que se presenta a sí mismo más como emprendedor que como político.

\section{Enmarcando el problema: rasgos de las campañas posmodernas en América Latina}

El concepto de campaña posmoderna y su modelo de comunicación política parten de los trabajos de Pipa Norris (2000). En ellos se describe por primera vez una nueva forma de campaña muy profesionalizada, con gran presencia de técnicas de marketing, híperpersonalizada y centrada en el targeting. Las campañas objeto de este estudio se enmarcan en un fenómeno global: la transformación de la comunicación política tradicional, la del modelo de campaña asociado a una estructura partidista, la de la propuesta de temas orientados a la solución de problemas «típicos» de la agenda pública y la de un esquema de comunicación orientado por la racionalidad y la argumentación. Este tipo de campaña ha dejado de existir y ha sido sustituido por una estructura de comunicación política basada en la hiperpersonalización de las campañas, en la emergencia dentro del debate público de temas que hasta ahora eran

[256] marginales y que representan demandas posmateriales (Inglehart, 1990), sobre todo, entre los públicos más jóvenes, en una fragmentación de propuestas y segmentación de mensajes que ayudan a alimentar el poderoso mecanismo de generación de clima político que son las redes sociales, y, por último, en un esquema de comunicación donde el relato sustituye de manera eficaz y eficiente al simple argumentario y a la letanía de propuestas de los partidos y candidatos tradicionales (Crespo, 2015, pp. 155-184).

Claudia López en Bogotá y Daniel Quintero en Medellín han sabido interpretar este nuevo escenario de campañas posmodernas y aplicar algunos de sus instrumentos, lo que representa una ruptura significativa con el modelo partidista hasta ahora vigente en los distintos ámbitos de competición, tanto nacional como subnacional. En estos casos aparecen las primeras expresiones de la desafección hacia el sistema y hacia la clase política tradicional. ¿Pero cuáles son los marcos teóricos de los que estas campañas toman su modelo? Dada la limitación de espacio, se exponen sintéticamente algunos de los principales elementos que explican estos nuevos estilos de campaña que, con cierto retraso, entran ahora en el escenario político colombiano de la mano de las elecciones regionales de 2019. 
El triunfo de las campañas posmodernas. Los casos de las alcaldías de Bogotá y Medellín...

\subsection{La hiperpersonalización de la campaña}

Es, sin duda, la personificación y personalización de la campaña el fenómeno que mejor define a las campañas posmodernas. La debilidad de los partidos políticos y el declive de las lealtades e identificaciones partidistas de la ciudadanía han conjurado a favor de una personalización cada vez más notable de las prácticas comunicacionales en el marco de las campañas electorales, incluso en sistemas de partidos tradicionalmente más institucionalizados como el de Francia, país que ha visto caer a marcas consolidadas como el Partido Socialista y triunfar a plataformas personalistas como la de Emmanuel Macron (Rahat y Kenig, 2018, p. 116).

El modelo de campaña centrado en el candidato ha sido reforzado por la desafección y la falta de confianza y credibilidad que se impone entre los ciudadanos hacia sus partidos e instituciones (Monsiváis, 2017). La aversión a todo lo relacionado con la política tradicional y a los «viejos» partidos propicia el surgimiento de nuevas formas de hacer y comunicar basadas en la personalización (Guerrero y Manzano, 2013, p. 69). Por ejemplo, cuando Daniel Quintero se presentó como candidato independiente, es decir, sin ninguna marca, más allá de toda ideología tradicional (Semana, 2019, septiembre 12), propuso constituir a su persona como marca y mensaje en sí de la campaña. Y esto lo pudo hacer porque los electores ya no establecen vínculos sentimentales de confianza a través de la ideología o de la adscripción partidista, sino que necesitan de un referente personal, de un hombre o mujer con historia propia elevada a relato político, para sentirse representados (Crespo y Carletta, 2013). El posicionamiento de la «marca candidato» permitió a los electores de Medellín identificarse de una manera más sencilla — casi intuitiva - con las ideas y la personalidad — atributosdel candidato. La creación de la marca, como sucedió en su día con la «U» de Uribe, provoca que el resto de los actores políticos de la competición pasen a un segundo plano, permitiendo a los ciudadanos asociar su voto a las ideas y atributos representados en la marca política del candidato (García, 2010, p. 46).

La personalización es parte intrínseca de la nueva comunicación política (Laguna, 2011) y «un reflejo de las profundas transformaciones sociales y políticas experimentadas por las sociedades industriales avanzadas [...], transformaciones que han reforzado la posición de los líderes y, en última instancia, han acentuado su significación electoral» (Rico, 2002, p. 12). A 
las campañas electorales se ha trasladado un modelo de comunicación y propaganda persuasiva centrado no en la identificación de los ciudadanos con los partidos o con las ideologías (Sánchez Galicia, 2010), sino en la acción política en los medios de comunicación, en especial en la televisión, la desaparición de la imagen de los partidos en favor de la de su líder o candidato, y la fuerte desideologización de los programas electorales (Sánchez Medero, 2009).

Los candidatos han pasado a convertirse en una razón decisiva de voto. En el contexto de una política personalizada, el mensaje hacia los electores ha sido encomendado casi de forma exclusiva a los candidatos (Orejuela, 2009, p. 62), que además de ser portadores de la oferta electoral del partido, deben hacer que esta sea creíble y ellos, en sí mismos, confiables. Por ello, el candidato debe actuar no solo como componente emocional del programa electoral, sino como elemento social (Canel, 2006, pp. 48-50). Los candidatos dejan de ser meros transmisores de los mensajes para ser «ejemplo y guía», siempre que exista una identificación del ciudadano y una confianza de este hacia el portador del mensaje (Bauman, 2002, pp. 77-78). Los atributos del candidato vinculan los temas y mensajes de campaña. Claudia López, una activista nacional contra la corrupción, partía con un crédito innegable en este asunto, que acertadamente situó como eje central de su discurso (Torrado, 2019, octubre 25). También ella, impulsora de normativas nacionales a favor de la movilidad sostenible, era la persona que podía abordar el problema de la contaminación del aire en la ciudad (El Tiempo, 2016, octubre 26).

La personalización de las campañas se basa en las características individuales o cualidades políticas del candidato —autoridad, experiencia, habilidades interpersonales, dotes morales o éticas, entre otras-. En las campañas posmodernas estos atributos básicos pueden ir acompañados de la encarnación en ese candidato de valores posmateriales que se pueden reflejar en los temas de la nueva política, como el feminismo, el ecologismo o el multiculturalismo. Estos atributos del candidato acaban primando sobre los temas o, al menos, se intenta que se asocien a los principales ejes temáticos de su campaña, permitiendo a través de estos enmarcar y posicionar al candidato en una esfera distintiva. El objetivo de ese posicionamiento es ocupar un espacio preferente en la mente de los votantes actuales o potenciales. El posicionamiento implica representar una idea diferenciadora como candidato en la mente del votante (Trout y Rivkin, 1996). Este posicionamiento es favorecido en las campañas no tradicionales por la ingente cantidad de 
mensajes que reciben los electores a través de los medios de comunicación, tanto por los tradicionales como por aquellos surgidos a raíz de las nuevas tecnologías, lo que implica una fragmentación de las propuestas de campaña y una segmentación de los públicos que recibirán los mensajes del candidato en ese afán por posicionar sus atributos asociados a las propuestas de campaña.

El hecho de que el candidato vaya en bicicleta, que sea una persona LGTBI o que haya sido un joven indignado que tiraba tomates a los políticos lo convierte en alguien que destacará en medio del ruido mediático. Tiene una historia y esa historia no la tiene nadie más en el espacio de competición. Además, las historias de Claudia López y Daniel Quintero poseen un importante contenido emocional, unos personajes bien definidos que lograron activar un marco cognitivo (Lakoff, 2007), ellos representan el futuro, mientras que todos lo demás son el pasado.

\subsection{La fragmentación de las propuestas y la segmentación de los mensajes}

En las campañas posmodernas no existe una «propuesta única», un problema sobre el que gire totalmente el núcleo de la campaña (Crespo, 2015, p. 163). Aunque los grandes temas estén presentes, como sucedió en las elecciones de 2019 con la violencia, el proceso de paz o el modelo de desarrollo (Telesur, 2019, octubre 26), los «nuevos temas», los «nuevos desafíos» sociales $y$, en especial, aquellos que los jóvenes reivindican, significan el cuore de este nuevo tipo de compromiso social y emocional que se da entre el candidato y sus electores o potenciales electores. Claudia López y Daniel Quintero hablaron en campaña con igual intensidad de temas tan diversos como el medioambiente, la regeneración política o la apuesta por las ciudades inteligentes. Las diversas propuestas tienen un hilo conductor, el progreso, pero apelan a blancos electorales distintos.

En la comunicación electoral posmoderna hay una pluralidad de mensajes y propuestas que varían dependiendo del momento de la campaña, de las contingencias que acontezcan (Luque, 1996, p. 187) y de los atributos que el candidato haya seleccionado para su posicionamiento en la competición electoral. Las imágenes, los eslóganes, las frases e ideas, y los discursos se fragmentan. Esta fragmentación se acompaña de una segmentación de los públicos, uno de los elementos centrales del nuevo marketing político aplicado en las campañas posmodernas (Valdez, 2010, 
p. 160), especialmente en aquellas que tienen un amplio desarrollo en el medio digital (Barko, 2009, p. 154).

Las campañas analizadas realizaron una segmentación de públicos evidente y muy estudiada. Ambos candidatos produjeron decenas de vídeos de campaña, algunos de ellos exclusivos para colectivos determinados como los jóvenes. En el caso de Daniel Quintero (2019, septiembre 15), esos spots para jóvenes se denominaron «Jóvenes, el futuro se parece a nosotros». Además de los jóvenes como blanco de ambas campañas, en la estrategia de Claudia López las mujeres cobraron una relevancia especial, articulando mensajes y propuestas para ellas. Claudia López incidió en la idea de que el Transmilenio debía ser un espacio seguro para mujeres (López, 2019, 8 de agosto), así segmentaba su mensaje sobre transportes que, en el mismo tema para un público más general o joven, orientaba hacia la contaminación o las condiciones del servicio. Su propuesta de implantar una «economía del cuidado» apela igualmente a un público femenino muy determinado (Claudia López, 2019, octubre 13). La fragmentación de las propuestas, no obstante, se sustenta bajo un relato general de campaña que es el relato del candidato.

La voracidad de los medios de comunicación, sobre todo de los audiovisuales, y la presencia cada vez más intensa de las redes sociales, reclama una multiplicidad de imágenes e ideas que fragmenten la propuesta única, y aunque se mantenga un eje predominante, se multiplican los contenidos diferenciados y diferenciadores. Esta fragmentación de las propuestas se traduce en una segmentación de los destinatarios, al mismo tiempo que lo visual se superpone frente a lo escrito. Al hacer una revisión de las redes sociales de ambos candidatos, casi todos sus mensajes de campaña vienen acompañados de breves vídeos o fotos que también ser refieren a temáticas concretas y escenarios específicos. Claudia López fue especialmente activa en redes sociales. Muestra de la fortaleza de su liderazgo en línea es que tiene en Twitter más seguidores que el presidente Iván Duque $-2,4 \mathrm{M}$ frente a $2 \mathrm{M}$, a septiembre de 2020-.

Como se afirmó anteriormente, en este sistema de fragmentación de las propuestas y segmentación de los destinatarios de estas, la herramienta que posibilita la existencia de una unidad de mensaje y la capacidad de aglutinar a los públicos en torno a una idea es el relato. El relato de un hombre independiente frente a las maquinarias o el relato de la mujer incorruptible 
que desafía lo establecido besando públicamente a su novia, la congresista Angélica Lozano, al momento de saber que ganó la elección (Fanlo, 2019, 28 octubre).

\subsection{El relato y el papel de las emociones en la nueva política}

A partir de mediados de la década de 1960 se fue consolidando un modelo anglosajón de marketing político-electoral tanto en Europa como en América Latina, basado en una oferta partidista centrada en propuestas concretas. La satisfacción de las necesidades objetivas de los electores sería la base del éxito de una campaña electoral (Martín, 2002, pp. 52-54). Sin embargo, este modelo fue superado, en especial a partir de la primera década del siglo Xxı, por un pensamiento crítico que sostenía que la clave de la persuasión no radica en la satisfacción de las necesidades objetivas de los electores, sino en la elaboración de relatos emotivos y apasionados (D'Adamo y García, 2016, p. 31), construidos en la mayoría de las ocasiones a partir del candidato: su pasado, sus características étnicas, su rol en la sociedad o su identidad sexual, entre otras.

En América Latina, este nuevo enfoque sostiene que la creciente heterogeneidad de la sociedad posmoderna invalida los mensajes clásicos - los destinados exclusivamente a un solo segmento de la sociedad-. Esto ha sido muy notorio entre las fuerzas de izquierda y se reflejó claramente en los escritos de Ernesto Laclau (2005, pp. 5-8): ante la pérdida del marco de referencia tradicional de la izquierda, el relato permite que diferentes sectores con realidades disímiles puedan encontrarse a partir de un discurso con significantes unificadores. Este relato, además, tiene un protagonista, el candidato, que es capaz de tender un puente con el pueblo. La agregación de demandas diversas se produce dentro de un relato amplio que apela a una mayoría social heterogénea que presenta un problema y que ofrece una solución.

En la última década, el storytelling se ha consagrado como la técnica que da forma y estructura al relato (Núñez, 2007). Esta construcción de relatos que marcan la agenda política ha sido denominada «narraquía» (Salmon, 2007, p. 124). El storytelling se elabora con la intención de apelar a los sentimientos y emociones al contar una historia que tiene como objetivo ofrecer explicaciones holísticas sobre los candidatos, el pasado, el presente y el futuro (D'Adamo y García, 2012, p. 32). 
El caso de Claudia López durante su etapa previa a la elección de 2019 es un clásico ejemplo de construcción de un relato mediante la técnica de la narraquía. Durante cuatro años, la entonces senadora de la Alianza Verde construyó una historia alrededor de la corrupción que intensificó en el momento de las elecciones, en especial con la iniciativa de consulta popular de 2018. Después de la firma de la paz, la lucha contra la corrupción intentó convertirse en el tema de mayor prioridad en la agenda pública, no solo de Bogotá, sino en todo el país (López, 2014, mayo 4). A esta historia política inmediata se incorporan otra serie de hitos personales previos como su participación en el movimiento estudiantil de la Séptima Papeleta, su faceta de estudiante becada o la figura referencial de la madre-maestra.

Surge, por tanto, una nueva propuesta en la comunicación posmoderna: la agenda temática del candidato se vertebra en torno a su relato personal y político. El discurso del candidato adquiere una centralidad absoluta en el marco de la campaña, incorporando no solo propuestas concretas en términos de políticas públicas, sino también la construcción de imaginarios identitarios y simbólicos, generando climas de opinión favorables a «su relato». ${ }^{1}$

Claudia López y Daniel Quintero tienen estéticas desenfadas, pero a la [262] vez profesionales. Se presentan como candidatos modernos para modernizar las ciudades. Candidatos para el futuro. Uno, ingeniero electrónico, quiere que la tecnología permita mejorar el bienestar; la otra, defensora del medio ambiente, nos conciencia de que no podemos seguir con los actuales niveles de contaminación. Por incidir en el segundo caso, la política bogotana se pudo apropiar de la bandera del activismo a través de un relato en el que contaba su historia de vida, su origen en una familia no adinerada, su orientación sexual, sus inicios como investigadora denunciando los nexos de la política colombiana con el paramilitarismo y cómo a partir de esto logró encarcelar a más de cincuenta políticos, sus logros como promotora de la consulta anticorrupción y las leyes que impulsó sobre este tema: «Nací en el centro de Bogotá y me crie, junto a mi madre y mis cinco hermanos, entre La Candelaria, Puente Aranda, Engativá y Ciudad Bolívar. De allá vengo, fue en esos rincones que empecé a conocer y a querer a Bogotá» (López, s. f. b). Daniel Quintero, un político joven, simbolizó, además del futuro, la ilusión, haciendo que el elector, al votarle, se sintiera bien.

\footnotetext{
${ }^{1}$ Para muchas campañas electorales, la agenda mediática sigue resultando vigente, pero los movimientos electorales emergentes en América Latina ponen de relieve un nuevo paradigma centrado en el relato como eje estratégico, por encima del clásico sistema comunicativo anglosajón (Crespo, 2015, p. 163).
} 
El triunfo de las campañas posmodernas. Los casos de las alcaldías de Bogotá y Medellín...

Como consecuencia de este contexto comunicativo, no se trata de tener los mejores argumentos para ganar la elección, sino de acertar en la activación de emociones y sentimientos. No obstante, para justificar la orientación de su voto hacia un determinado candidato, el elector se afana en encontrar razones sólidas que permitan darle coherencia, no siendo irrelevante la información «racional» para dar consistencia a las emociones que en realidad guían su acción. Incluso el voto ideológico no necesita de una argumentación avanzada, sino que se sustenta en las emociones y los sentimientos que se generan a partir del partido o del candidato (Crespo, Garrido, Carletta y Riorda, 2011, pp. 116-121). En estas dos campañas municipales hay una emoción básica: hacer lo imposible, cambiar la historia, hacer algo nuevo, hacer algo por primera vez. La fuerza de la primera vez es consustancial al ser humano e impulsarla en candidaturas nuevas es garantía de éxito.

Claudia López logró, usando un lenguaje diferente al de los políticos tradicionales, activar a la gente que pedía castigo para los corruptos. Se presentó como una mujer valiente que podía combatir a los corruptos, que los pondría en su lugar; una mujer preparada, fuerte y eficiente. El mensaje positivo quedaba claro: ella y su partido eran los que se habían dedicado a combatir la corrupción mientras todos los «otros» simbolizaban la política tradicional y corrupta. Generó la esperanza de una administración decente para Bogotá en la que las cosas funcionarían porque formaría un equipo sin políticos corruptos. Al mismo tiempo, Daniel Quintero era «el hombre hecho a pulso», de vendedor ambulante a estudiante en Boston, por eso quería oportunidades para todos; y también era el hombre «libre e independiente» del poder, alguien que no debía estar compitiendo por la Alcaldía, pero que, contra todo pronóstico, lo hizo, porque ya nada era como antes. Por eso le temen, dijo en su campaña. Un «relato desafío» (D’Adamo y García, 2012, p. 32) con un componente aspiracional que resume dos campañas de tono positivo y amable.

Si tradicionalmente los sentimientos han sido usados en política a través de campañas negativas, azuzando, por ejemplo, el miedo a perder algo o a lo desconocido, ahora resulta que las emociones positivas, la alegría o la esperanza, también pueden cobrar un papel de relevante efectividad en el diseño de las campañas electorales posmodernas: «las emociones más importantes para el comportamiento político son el entusiasmo (y su opuesto, la depresión) y el miedo (y su contrario, la calma)» (Castells, 2009, p. 203). 


\section{Los casos}

\subsection{Claudia López por la Alcaldía de Bogotá}

Claudia López presentó su candidatura a la Alcaldía de Bogotá tras haber sido senadora (2014-2018). Fue en 2018 una de las promotoras de la Consulta Anticorrupción (El Espectador, 2018, junio 6), un hito en su relato como candidata que se suma a su destacada y feroz crítica al fenómeno de la «parapolítica». La acción ciudadana de la Consulta Anticorrupción se situó fuera de las estructuras políticas tradicionales y aunque no logró por poco su objetivo abrió un nuevo tiempo en la política del país. Precisamente, la lucha contra la corrupción y el crédito ganado como una de las impulsoras de la consulta, se convirtió en un issue — temas de campaña electoral (Garrido, 2016) - distintivo de su campaña. Un interesante paralelismo entre Claudia López y Daniel Quintero se puede encontrar en este tema, pues el candidato de Medellín también actuó como activista a favor de la consulta.

Claudia López y Daniel Quintero son dos candidatos progresistas ajenos a la política tradicional y ese es su principal valor. Son líderes locales atípicos, no solo por su perfil personal, sino también por su discurso (La República, 2019, octubre 27). No hablan de lo que se solía hablar en la política colombiana, descubren nuevos espacios de interés y desde ellos construyen imaginarios transversales.

Claudia López se enfrentó a tres jóvenes candidatos: el liberal Carlos Fernando Galán, hijo del asesinado candidato presidencial Luis Carlos Galán, por Bogotá Para La Gente — grupo significativo de ciudadanos-; Hollman Morris, antiguo periodista y escudero del líder izquierdista y exguerrillero del M-19 Gustavo Petro por Colombia Humana, y el conservador Miguel Turbay, nieto del expresidente Julio César Turbay (1978-1982), secretario del gobierno distrital de la alcaldía saliente de Enrique Peñalosa (1998-2000 y 2016-2019) - grupo significativo de ciudadanos Avancemos-.

De Claudia López se ha destacado su condición de persona LGTBI, a veces poniendo en duda la aceptación que podría tener esto en un país de talante conservador (Argüello, 2019, octubre 28). Lo cierto es que ser la primera mujer electa para la Alcaldía de la capital de Colombia y además hacerlo hablando abiertamente de su orientación sexual, más que un problema, terminó siendo un factor de diferenciación que resumió en la 
mente del elector por qué votar a esta candidata era votar por algo novedoso — los atributos del candidato sintetizan el mensaje—. Resulta, además, que Claudia López es vista todavía como una de las políticas mejor preparadas de su generación (El Espectador, 2019, octubre 28): se graduó en finanzas, gobierno y relaciones internacionales en la Universidad Externado de Colombia, posee una maestría en Administración Pública y Política Urbana en la Columbia University de Nueva York y un doctorado en Ciencia Política de la Northwestern University de Chicago.

La candidata muy pronto dirigió su campaña hacia dos sectores estratégicos: los jóvenes y las mujeres. La senadora combativa, la mujer cercana a los movimientos sociales y a los estudiantes se presentaba para ser «Alcaldesa de una», prometiendo mantenerse «incorruptible» (Torrado, 2019, octubre 25). Si su ethos político ha estado marcado por cierta belicosidad en el pasado, la campaña a la Alcaldía, consciente de la necesidad de construir una amplia mayoría social, estuvo caracterizada por un cambio de actitud (Semana, 2019, noviembre 4), que la llevó, tras unas elecciones internas de la Alianza Verde en las que derrotó al exguerrillero y exconstituyente del M-19, Antonio Navarro Wolff, a cobijarse en el exalcalde de Bogotá y figura intelectual pública, Antanas Mockus, integrante del sector más centrista del progresismo. Esto implicó la disminución de sus polémicas, que a menudo le han traído triunfos, pero también le han obligado a retractarse. Se diseñó una campaña completamente personalista y poco ideológica, conciliatoria frente a sus adversarios, con una lógica más propia de la comunicación de gobierno que de la comunicación electoral, buscando unir, y en la que primero se percibió como ganadora, para luego perder ese lugar en las encuestas frente a Galán, retomando el liderazgo al final.

El propio lema de la campaña, «Alcaldesa de una», anticipaba la voluntad de ampliar su base electoral previsible a partir de una política de cuidados tan propia del feminismo posmoderno (Piedra, 2003). Superar la división es una idea fuerza de la campaña que conecta directamente con la aspiración de reconciliación nacional. En diversos discursos, la candidata afirmó querer construir una ciudad que cuidara y abrazara, una visión amable de la política que contrasta con la polarización que domina al país (Pérez, 2018, pp. 17), protagonizada por la izquierda tradicional y el uribismo. Precisamente, el senador de Colombia Humana, Gustavo Petro, mentor de Hollman Morris que no se unió a Claudia López pese al clamor de la izquierda y a que ella sí lo hizo en las pasadas presidenciales en la segunda vuelta con Petro-, manifestó 
en Twitter, tras conocer los resultados, que «En Bogotá gana Claudia López. No nos representa. El movimiento Colombia Humana será independiente a su gobierno» (Petro, 2018, 27 octubre).

Esta alcaldesa que se mueve en bicicleta prometía erradicar el machismo, el racismo, el clasismo y la homofobia, recordando que ella era la hija de una maestra sindicalista y de un padre humilde (López, 2018, 1.o de mayo), una identidad obrerista presente en el fondo del discurso para activar a sectores de la izquierda. Desde la campaña de Claudia López estaban dispuestos a ganar sin buscar el enfrentamiento en su discurso, es más, apelaban a la unidad bajo una misma causa, en un tono de campaña alegre y positivo, por momentos festivo, más de poesía que de prosa. Eso sí, supieron dibujar bien que su candidata no era parte del establishment, algo que resolvía la batalla entre ella y Carlos Fernando Galán, otro candidato portador de un relato inspirador (Oquendo, 2019, octubre 26). Galán era pasado, un pasado triste al que muchas personas no querían volver, ni siquiera para resolverlo justamente. López era el futuro, el metafórico aire limpio.

La candidata ecofeminista demostró que era posible disputar [266] campañas a la vieja política desde fuera de las estructuras tradicionales y con una agenda progresista, no teniendo que recurrir exclusivamente a la construcción populista amigo-enemigo. Al querer distanciarse también de los sectores de la izquierda tradicional, Claudia López verificó que, especialmente en ámbitos locales, los temas y el liderazgo superan con creces a la identificación ideológica o partidista como factor de voto. Sobre este particular, conviene citar el reciente estudio de Carmen Ortega y Fátima Recuero (2020) en el que se investiga el factor del liderazgo en las elecciones municipales españolas, aunque resulta extrapolable. Las autoras encuentran que «en el caso de las elecciones municipales, los votantes estaban fuertemente influenciados por candidatos específicamente locales, así como por líderes nacionales y regionales, aunque en menor medida»; esto las lleva a afirmar que «los resultados obtenidos demuestran la gran importancia de los líderes locales, que no se encuentran subordinados a los líderes nacionales de sus partidos en términos de su influencia electoral» (p. 138).

La candidatura de Claudia López, al mismo tiempo que impulsaba un relato personal potente, posicionó temas novedosos que solo ella podía tratar: 
la calidad del aire, el sistema de transporte y la movilidad sostenible — con una defensa a ultranza del metro y desplazando al Transmilenio, sistema de buses articulados, como eje del sistema-, la salud y educación públicas de calidad o la seguridad fueron algunas cuestiones destacadas en su discurso. ${ }^{2}$

De especial interés es el ejercicio de triangulación (Morris, 2003) que López hizo con la cuestión de la seguridad y la convivencia, ofreciendo firmeza en la lucha contra la delincuencia como prioridad. Se seleccionó un tema propio del ámbito conservador para responder, a su vez, a una preocupación de su electorado, la inseguridad de las mujeres y la violencia machista. Respecto a la seguridad, la candidata unió su discurso al tema de la corrupción y mostró que ella era una líder fuerte para luchar contra el robo en las instituciones públicas o contra el delincuente común (Claudia López Alcaldesa, 2019, octubre 24).

Tabla 1. Resultados de las elecciones para la Alcaldía de Bogotá, 2019.

\begin{tabular}{|l|l|c|}
\hline \multicolumn{1}{|c|}{ Candidato } & \multicolumn{1}{c|}{ Partido o movimiento político } & \multicolumn{1}{c|}{ Votos } \\
\hline Claudia Nayibe López & Coalición Claudia Alcaldesa & $1109362(35,26 \%)$ \\
\hline Carlos Fernando Galán & $\begin{array}{l}\text { Grupo significativo de ciudadanos } \\
\text { Bogotá Para La Gente }\end{array}$ & $1022874(32,51 \%)$ \\
\hline Hollman Morris & Coalición Colombia Humana & $95163(12,09 \%)$ \\
\hline Miguel Uribe Turbay & Coalición Avancemos & $22738(2,89 \%)$ \\
\hline
\end{tabular}

Fuente: elaboración propia a partir de Registraduría Nacional del Estado Civil (s. f.).

Claudia López fue la ganadora por mayoría simple, quien se presentó bajo una coalición que comprimía a su partido, Alianza Verde, junto al izquierdista Polo Democrático Alternativo yal independiente grupo significativo de ciudadanos Activista del precandidato Luis Ernesto Gómez. Pese a que Carlos Fernando Galán se presentó como grupo significativo de ciudadanos, obtuvo el respaldo de su antiguo partido, Cambio Radical. Hollman Morris fue respaldado por su propio partido, Colombia Humana, el Movimiento Alternativo Indígena y Social, la Unión Patriótica y el Partido Comunista

\footnotetext{
${ }^{2}$ La página de campaña de Claudia López (s. f. a) muestra al inicio los temas de campaña y algunas de las narrativas más significativas de su discurso. Se recomienda visitarla para tener una idea más amplia de la estrategia seguida.
} 
Colombiano. Finalmente, Miguel Uribe, bajo la Coalición Avancemos y como exsecretario de gobierno de la alcaldía de Enrique Peñalosa, se valió de su propio grupo significativo de ciudadanos y del respaldo de la derecha colombiana.

\subsection{Daniel Quintero por la Alcaldía de Medellín}

Daniel Quintero Calle es un ingeniero electrónico nacido en las zonas humildes de Medellín que se presentó como independiente a la Alcaldía de esta ciudad, feudo del uribismo. Daniel Quintero fue viceministro de Economía Digital (2016-2017) del Ministerio de Tecnologías de la Información y las Comunicaciones durante el gobierno de Juan Manuel Santos, luego de liderar un movimiento joven de indignación con la clase política a través del Partido del Tomate (Semana, 2016, julio 26).

Este candidato apeló, como Claudia López, a la unidad, lo que él llamo «política del respeto» para superar la división tradicional entre izquierda y derecha (Quintero, 2019, 7 de septiembre), tras una campaña especialmente dura en su contra. Su estrategia electoral describe significativos puntos de encuentro con la de Claudia López. En primer lugar, la apuesta por un tono

[268 ] respetuoso, abandonando la conflictividad. Tanto es así que en su discurso de victoria prometió «sanar las heridas que dejó la polarización»: «No podemos dejar que Medellín quede atrapado en ese pantano de polarización. Nosotros no somos ni el de Uribe ni el de Fajardo ni el de Petro ni el de Duque» (Tamayo, 2019, octubre 27). También en él se advierte un relato personal que sintetiza el mensaje político. El candidato es un hombre hecho a sí mismo contra diversas dificultades vitales y une el espíritu emprendedor más popular a la preparación académica en grandes universidades. Daniel Quintero es, sumado a lo anterior, un hombre valiente, rebelde, dispuesto a denunciar las injusticias, aunque eso le haya podido llegar a ocasionar amenazas de muerte. ¿Quién no quiere a un héroe como alcalde?

Este liderazgo se construye como representación de una «política joven» orgullosa de no tener jefes partidistas y de ser un movimiento de la gente. El valor de la independencia se convirtió en el centro del mensaje, en un momento de especial distanciamiento ciudadano respecto a las ofertas clásicas. Repetidamente en campaña el candidato prometió que no iba a gobernar para partidos, jefes políticos o maquinarias (Quintero, 2019, 15 de 
octubre). Esto trasladó a los electores una sensación de que votar por Daniel Quintero no era, en realidad, votar por un político, sino por algo inédito. De hecho, se lanzó el spot «Somos La Nueva Política» (Quintero, 2019, octubre 21) en el que el candidato repite un mantra de su relato: «se supone que yo no debía estar aquí». Esta pieza audiovisual, que superó las doscientas mil visualizaciones en YouTube, tiene como escenario un autobús público en el que el candidato, rodeado de jóvenes, afirma estar a un voto de cambiar la historia de Medellín. El hartazgo ciudadano con los políticos tradicionales hizo posible algo, en principio, inusual: que la ciudad apostara por un independiente. Simultáneamente, tanto Daniel Quintero como Claudia López incorporaron a su agenda temas novedosos. Se habló asiduamente de ecología y contaminación, prometiendo convertir a Medellín en una ecociudad con un mejor sistema de movilidad (Daniel Quintero Calle, 2016, octubre 16). También supo comprender la importancia que en este nuevo tiempo tiene la diversidad y cómo esto se podía unir a su mensaje de tolerancia, defensa de los derechos sociales y de la paz.

La candidatura independiente se instaló en el imaginario colectivo con una importante apuesta por la modernización. «Futuro» fue una palabra clave en la articulación del discurso de Daniel Quintero, hasta tal punto que su idea de convertir a Medellín en Valle del Software acaparó buena parte de la comunicación de propuestas de campaña, en una línea general de impulsar las ciudades inteligentes —smart cities— (Telemedellín, 2020, enero 1.․o. La puesta en escena de Daniel Quintero es, por un lado, de indignación y, por otro, de renovación joven. Esto le ha permitido dar uno de los saltos cualitativos más importantes en la política nacional, y todo ello afirmando que su campaña «no es de izquierdas ni de derechas, es independiente», en relación con el grupo significativo de ciudadanos que ha impulsado como plataforma.

Daniel Quintero tuvo como principal rival a Alfredo Ramos del Centro Democrático, el partido del expresidente y principal barón electoral en Antioquia, Álvaro Uribe, a su vez apoyado por una coalición derechista de los partidos Conservador, MIRA, Alianza Social Independiente y Partido de la $U$. El resto de los rivales, en una suerte de combinación de antiguas figuras políticas, burócratas o activistas sociales, se movieron entre dichas opciones independientes y partidistas, terminando de barrer el voto de izquierda a derecha. 
Tabla 2. Resultados de las elecciones para la Alcaldía de Medellín, 2019.

\begin{tabular}{|l|l|c|}
\hline \multicolumn{1}{|c|}{ Candidato } & \multicolumn{1}{|c|}{ Partido o Movimiento político } & \multicolumn{1}{c|}{ Votos } \\
\hline Daniel Quintero Calle & $\begin{array}{l}\text { Grupo significativo de ciudadanos } \\
\text { Independientes }\end{array}$ & $304034(38,56 \%)$ \\
\hline Alfredo Ramos & Centro Democrático & $235105(29,88 \%)$ \\
\hline Santiago Gómez Barrera & $\begin{array}{l}\text { Grupo significativo de ciudadanos } \\
\text { Seguimos Contando con Vos }\end{array}$ & $95163(12,09 \%)$ \\
\hline Juan David Valderrama López & $\begin{array}{l}\text { Grupo significativo de ciudadanos } \\
\text { Todos Juntos }\end{array}$ & $22738(2,89 \%)$ \\
\hline Beatriz Elena Rave & Alianza Verde & $14254(1,81 \%)$ \\
\hline Víctor Javier Correa Vélez & Polo Democrático Alternativo & $10119(1,28 \%)$ \\
\hline Gemma María Mejía Izquierdo & Colombia Justa Libres & $9441(1,19 \%)$ \\
\hline Juan Carlos Vélez Uribe & $\begin{array}{l}\text { Grupo significativo de ciudadanos } \\
\text { Medellín Avanza }\end{array}$ & $6977(0,88 \%)$ \\
\hline Jairo Herrán Vargas & Colombia Humana-UP & $2303(0,29 \%)$ \\
\hline Luis Guillermo Hoyos Meneses & Partido de Reivindicación Étnica & $1292(0,16 \%)$ \\
\hline Jorge Orlando Gutiérrez Serna & Colombia Renaciente & $999(0,12 \%)$ \\
\hline Luis Fernando Muñoz Ramírez & Alianza Democrática Afrocolombiana & $338,43 \%)$ \\
\hline
\end{tabular}

Fuente: elaboración propia a partir de Registraduría Nacional del Estado Civil (s. f.).

\section{Discusión}

Las campañas ganadoras de Claudia López y Daniel Quintero en las dos principales ciudades de Colombia demuestran que los estilos de la nueva política no solo se constituyen en alternativas, sino en una manera ventajosa de superar el agotamiento de la agenda política tradicional. Campañas como las analizadas ejemplifican vías novedosas que se abren en los escenarios políticos locales, no solo en Colombia, sino en el conjunto de Latinoamérica y también en Europa, ${ }^{3}$ para afrontar la desafección hacia

\footnotetext{
${ }^{3}$ Las campañas de Anne Hidalgo para la Alcaldía de París (2020), de Manuela Carmena para la Alcaldía de Madrid (2019) o de la joven congresista demócrata Alexandria Ocasio-Cortez (2018) pueden considerarse exponentes internacionales recientes del modelo de campañas posmodernas postulado.
} 
los modelos tradicionales de hacer política y de comunicar en campaña. Las campañas de polarización extrema, de desconexión con los asuntos que reclaman los electores y la ausencia de relatos positivos que promuevan la esperanza están dando un paso al costado en los nuevos modelos de campañas posmodernas que tienen su mejor escenario en el marco de las elecciones locales, con casos recientes y similares a los de Colombia en España, como el de Ada Colau en Barcelona, o en Italia, con Virginia Elena Raggi, alcaldesa de Roma por el Movimiento 5 Estrellas.

Algunos de los factores centrales de la comunicación posmoderna en Colombia ya tenían un precedente con la postulación de Antanas Mockus en 2010, en la denominada Ola Verde (Rincón, 2011): personificación de la campaña, creación de marca y, sobre todo, la introducción de las nuevas tecnologías como medio de comunicación con los electorados más jóvenes. Sin embargo, en los casos de Claudia López y Daniel Quintero, lo absolutamente novedoso es que el relato personal permea toda la campaña y su estrategia comunicativa, ahora más segmentada, para incluso subordinar la potente comunicación digital a esta nueva lógica de acercar «nuestra» historia al ciudadano. Esta apuesta comunicativa permite en ambos casos enmarcar y reforzar aún más su relato a partir de los medios digitales, los cuales acentúan la tendencia a la personalización y operan una pareja individualización del votante-usuario, ya no como un mero receptor de narrativas e imágenes, sino como un nodo que crea y difunde sus propios contenidos y entabla una relación «personal» con los candidatos a las alcaldías (Crespo et al., 2011, pp. 215-216).

Desde el punto de vista del desafío que la nueva política y la comunicación posmoderna plantea a los partidos tradicionales, Claudia López afrontó un proceso más prudente que el de Daniel Quintero, pero no sin importancia. Ella finalmente provenía de la Alianza Verde como promotora de su candidatura y fue respetuosa de un proceso de selección interna, todo lo contrario respecto al origen por fuera del sistema de partidos de Daniel Quintero. No obstante, el personalismo de Claudia López se impuso y con él sus atributos como única mujer en concurrencia con posibilidades de ganar, con una agenda novedosa y un ethos poco convencional. Todo ello la llevó a configurar una campaña inusual, exitosa y renovadora, en el marco de las tendencias comunicativas que se están imponiendo, basadas en un liderazgo de la visibilidad y en el establecimiento de poderosos nexos emocionales entre los candidatos y sus electores o potenciales electores (Crespo y Carletta, 2013, pp. 92-93). 
Daniel Quintero, por su parte, es heredero de la aparición de candidaturas independientes protagonizadas por «antipolíticos», una tónica general en la región, tanto en las elecciones nacionales como subnacionales desde la década de 1990. No es el único que ha intentado ser agente de renovación personalista en Antioquia y el país, incluyendo la pasada campaña a la Alcaldía en su ciudad, pero Daniel Quintero añade al marco de los discursos típicos de los outsiders un elemento nuevo, un relato propio que transciende la antipolítica, en tanto recurso de apelación negativa, y se centra en mensajes modernos basados no en generar ira, sino futuro y esperanza. Su mérito adicional, y el que hay recordar tras su victoria política, es nada menos que haber derrotado desde estas nuevas formas de comunicación y con todo en contra al disciplinado uribismo en su propio territorio.

Las agendas de campaña en Bogotá y en Medellín, como las encararon Claudia López y Daniel Quintero, se diferenciaron de los discursos y estrategias tradicionales que han movilizado las campañas en las elecciones legislativas y presidenciales colombianas. El reciente trabajo de Kent Eaton (2020) sobre el mandato de Gustavo Petro como alcalde de Bogotá (20122015) demuestra que no es la primera vez que esta ciudad se aleja de las tendencias generales del país e intenta marcar su propio camino, pero la campaña de Petro sí puede enmarcarse en un modelo de comunicación no completamente posmoderno.

La nueva política y sus nuevas formas de comunicación, centradas en los candidatos, con relatos emocionales e inclusivos, alejados de los interminables repertorios de promesas siempre incumplidas de los viejos candidatos y abordando los «nuevos» temas que afrontan los ciudadanos de estas capitales, funcionó y ayudó a «pausar» los problemas, desafíos y narrativas que enfrentan Colombia y ambas ciudades desde hace décadas y que, sin que dejaran de existir, distraían o agotaban al votante de las elecciones puntuales de los nuevos alcalde o alcaldesa.

\section{Conclusiones}

Las elecciones locales de Bogotá y Medellín en 2019, entre otros casos de Estados Unidos, América Latina y Europa, han sido un escenario privilegiado para mostrar algunos de los rasgos más sobresalientes de las nuevas formas de comunicación política en el marco de las campañas electorales. 
El primer aspecto para destacar es la centralidad que han alcanzado los candidatos como vertebradores de los mensajes en la campaña. Se puede concluir que las de Claudia López y Daniel Quintero han sido campañas de candidato y que ambos se convirtieron en los principales canalizadores del voto. Es cada vez más frecuente encontrar estos contextos de política fuertemente personalizada, donde el mensaje hacia los electores es emitido casi de manera exclusiva a través de los líderes.

El segundo aspecto en estas nuevas campañas posmodernas es el papel que desempeñan las tecnologías de la comunicación en todo el proceso de elaboración, transmisión y retroalimentación del mensaje. En el caso de las dos campañas estudiadas, se trata de la posibilidad de usar estas herramientas para fragmentar los mensajes y segmentar a las audiencias. La comunicación política ha abierto el camino para ir un paso más allá de la simple integración de las acciones de campaña en el mundo digital.

Por último, el tercer aspecto, y quizá el más sobresaliente en los dos casos analizados, es la presencia en la nueva comunicación política de una narrativa de campaña centrada en el relato emocional. La comunicación persuasiva, sobre todo de Claudia López, pero no en menor medida de Daniel Quintero, se ha basado en la construcción de relatos emotivos, apasionados y míticos. Los ciudadanos quieren oír una historia, no más listas de propuestas, cuestión a la que se han prestado los medios de comunicación.

Estos cambios en la comunicación política son fruto de nuevos tipos de electores que no responden comunicacionalmente a los viejos estereotipos de fácil segmentación. Colombia, un país que no había sido terreno fértil para la adopción de las pautas y rutinas de la comunicación política posmoderna, y donde el modelo de campaña tradicional ha sido hegemónico, incluso tras el intento rupturista de Mockus en 2010, se convirtió en escenario de dos campañas que expresan a la perfección algunos de los principales rasgos de este modelo de comunicación. Las candidaturas de Claudia López y de Daniel Quintero, más allá de cualquier otro significado, no solo rompen con la política tradicional, expresan la discontinuidad tanto en los contenidos como en las formas conservadoras de relacionarse con los ciudadanos. Sin duda, la modernización de los públicos ha afectado el desarrollo de las estrategias de competición de los partidos y en, en este caso, de los candidatos. La vieja forma de hacer política y de comunicar en campaña no ha desaparecido, pero ha dejado de ser hegemónica también en Colombia. 


\section{Referencias bibliográficas}

1. Argüello, Francisco. (2019, octubre 28). Bogotá elige a su primera alcaldesa: lesbiana, ecologista y símbolo de la lucha contra la corrupción. El Mundo. Recuperado de https://www.elmundo.es/internacional/2019/10/28/5db6b56b21 efa0b1438b46 0e.html

2. Barko Germany, Julie. (2009). The Online Revolution. In: Johnson, Dennis W. (comp.). Campaigning for President 2008: Strategy and Tactics, New Voices and New Techniques (pp. 147-160). New York: Routledge.

3. Bauman, Zygmunt. (2002). Modernidad líquida. Buenos Aires: Fondo de Cultura Económica.

4. Canel, María José. (2006). Comunicación política: Una guía para su estudio y práctica. Madrid: Tecnos.

5. Castells, Manuel. (2009). Comunicación y poder. Madrid: Alianza.

6. Claudia López. (2019, octubre 13). Propuestas Mujeres, \#ClaudiaAlcaldesaDeUna. [Archivo de video]. Recuperado de https://www.youtube. $\mathrm{com} /$ watch? $\mathrm{v}=$ pMbjSwzqtYQ

7. Claudia López Alcaldesa. (2019, octubre 24). La Lucha contra la corrupción, necesita alguien fuerte!! [Archivo de video]. Recuperado de https://www.youtube. $\mathrm{com} /$ watch? $\mathrm{v}=$ jg0O37sGiJU

8. Consejo Nacional Electoral Colombia. (2019, enero 24). Grupos Significativos.

[274 ] Recuperado de https://www.cne.gov.co/tramites-y-servicios/grupos-significativos

9. Crespo, Ismael. (2015). ¿Cómo cambia la comunicación política? Reflexiones y tendencias a partir de las experiencias de América Latina. Revista Democracias, 3, pp. 155-184.

10. Crespo, Ismael y Carletta, Ileana. (2013). Liderazgo y estrategias de comunicación en las campañas electorales en América Latina. En: Crespo, Ismael y del Rey, Javier (eds.). Comunicación política y campañas electorales en América Latina (pp. 85-104). Buenos Aires: Biblos.

11. Crespo, Ismael; Garrido, Antonio; Carletta, Ileana y Riorda, Mario (2011). Manual de comunicación política y estrategias de campaña. Candidatos, medios y electores en una nueva era. Buenos Aires: Biblos.

12. Daniel Quintero Calle. (2019, septiembre 15). Jóvenes, el Futuro se Parece a Nosotros \#1. [Archivo de video]. Recuperado de https://www.youtube.com/ watch? $v=h \times w J t S G 5 z f 0$

13. Daniel Quintero Calle. (2016, octubre 16). Vamos a hacer de Medellín una ecociudad. Facebook. [Archivo de video]. Recuperado de https://www.facebook. com/DQuinteroCalle/videos/vamos-a-hacer-de-medell\%C3\%ADn-una-ecociudadmediante-la-implementaci\%C3\%B3n-de-estrategia/465353527401950/

14. D'Adamo, Orlando y García Beaudoux, Virginia. (2012). Storytelling. El relato político. Más Poder Local, 9, pp. 32-33. 
El triunfo de las campañas posmodernas. Los casos de las alcaldías de Bogotá y Medellín...

15. D’Adamo, Orlando y García Beaudoux, Virginia. (2016). Comunicación Política: narración de historias, construcción de relatos políticos y persuasión. Comunicación y Hombre, 12, 23-39.

16. Eaton, Kent. (2020). Bogotá's Left Turn: Counter-Neoliberalization in Colombia. International Journal of Urban and Regional Research, 44, pp. 1-17. https:// doi.org/10.1111/1468-2427.12855

17. El Espectador. (2018, junio 6). «La real batalla apenas comienza y es en las urnas»: Claudia López sobre consulta anticorrupción. Recuperado de https://www. elespectador.com/noticias/politica/la-real-batalla-apenas-comienza-y-es-en-las-urnasclaudia-lopez-sobre-consulta-anticorrupcion/

18. El Espectador. (2019, octubre 28). Claudia López, primera alcaldesa electa en la historia de Bogotá. Recuperado de https://www.elespectador.com/noticias/bogota/ claudia-lopez-primera-alcaldesa-electa-en-la-historia-de-bogota/

19. El Tiempo. (2016, octubre 26). La nueva ley que impulsa uso de la bicicleta en el país. Recuperado de https://www.eltiempo.com/bogota/ley-que-impulsa-uso-dela-bicicleta-en-el-pais-42580

20. Fanlo, Isaías. (2019, 28 octubre). La fuerza de un beso. Revista Arcadia. Recuperado de https://www.revistaarcadia.com/opinion-online/articulo/la-fuerza-delbeso-de-claudia-lopez-y-angelica-lozano/78654/

21. García Jiménez, Leonarda. (2010). Y el protagonista es el candidato: la personalización como enfoque en comunicación política. En: Zamora, Rocío (coord.). El candidato marca. Cómo gestionar la imagen del líder político (pp. 27-50). Madrid: Fragua.

22. Garrido, Antonio. (2016). Temas de campaña (issues). Diccionario Enciclopédico de Comunicación Política. Recuperado de http://www.alicecomunicacionpolitica.com/wikialice/index.php/Temas_de_campa\%C3\%B1a_(issues)

23. Guerrero García, Jorge y Manzano Fernández, M. Ángeles. (2013). La excelencia en el liderazgo político 2.0. En: Crespo, Ismael y del Rey, Javier (eds.). Comunicación política y campañas electorales en América Latina (pp. 69-84). Buenos Aires: Biblos.

24. Inglehart, Ronald. (1990). Culture Shift in Advanced Industrial Society. New Jersey: Princeton University. https://doi.org/10.1515/9780691186740

25. Laclau, Ernesto. (2005). La razón populista. Buenos Aires: Fondo de Cultura Económica.

26. Laguna Platero, Antonio. (2011). Liderazgo y comunicación: la personalización de la política. Análisis, 43, pp. 45-57.

27. LaKoff, George. (2007). No pienses en un elefante. Lenguaje y debate político. Madrid: Complutense.

28. La República. (2019, octubre 27). Tiempo para cambiar la partitura. Recuperado de https://www.larepublica.co/opinion/editorial/tiempo-para-cambiar-lapartitura-2925819 
29. López, Claudia [ClaudiaLopez]. (2014, mayo 4). El mayor problema de Colombia hoy no son las FARC, es la corrupción. [Tuit]. Recuperado de https://twitter. com/claudialopez/status/440636854145396736

30. López, Claudia [ClaudiaLopez]. (2018, $1 .^{\circ}$ de mayo). Soy orgullosamente hija de una maestra, sindicalista y un padre humilde trabajador incansable. Llevo en la sangre y el alma las luchas de los trabajadores. Con \#FajardoPresidente vamos por empleo digno, formal, bien remunerado, con salud y pensión. [Tuit]. Recuperado de https://twitter.com/claudialopez/status/991349259965550592

31. López, Claudia [ClaudiaLopez] (2019, 8 de agosto). ¡No conciliaremos ninguna forma de violencia contra las mujeres! No más mujeres acosadas en el Transmilenio ni maltratadas en sus hogares, en la calle o en el espacio público [Tuit]. Recuperado de https://twitter.com/claudialopez/status/1159521683792977920

32. López, Claudia. (s. f. a). Claudia Alcaldesa De Una. Recuperado de https:// claudia-lopez.com/

33. López, Claudia. (s. f. b). Mi historia. Claudia Alcaldesa De Una. Recuperado de https://claudia-lopez.com/mi-historia/

34. Luque, Teodoro. (1996). Marketing político. Un análisis de intercambio político. Barcelona: Ariel.

35. Martín Salgado, Lourdes. (2002). Marketing político: ciencia y arte de la persuasión en democracia. Barcelona: Paidós.

36. Monsiváis Carrillo, Alejandro. (2017). La desafección representativa en

[276] América Latina. Andamios, 14 (35), pp. 17-41. https://doi.org/10.29092/uacm. v14i35.570

37. Morris, Dick. (2003). Juego de poder. Buenos Aires: El Ateneo.

38. Norris, Pipa. (2000). A Virtuous Circle. Political Communications in Postindustrial Societies. Cambridge: Cambridge University. https://doi.org/10.1017/ CBO9780511609343

39. Núñez, Antonio. (2007). ¡Será mejor que lo cuentes! Los relatos como herramienta de comunicación. Storytelling. Barcelona: Empresa Activa.

40. Oquendo, Catalina. (2019, octubre 26). Carlos Fernando Galán y la promesa de no polarizar a Bogotá. El País. Recuperado de https://elpais.com/ internacional/2019/10/24/actualidad/1571890032 797033.html

41. Orejuela Seminario, Sandra. (2009). Personalización política: la imagen del político como estrategia electoral. Revista de Comunicación, 8, pp. 60-83.

42. Ortega Villodres, Carmen y Recuero López, Fátima. (2020). Liderazgo político y elecciones municipales: ¿nacionalización, regionalización o localismo. Revista Española de Investigaciones Sociológicas, 169, pp. 123-140. https://doi.org/10.5477/ cis/reis.169.123

43. Pérez M., Carlos Andrés. (2018). La elección en la que Uribe se consolidó como el político más efectivo de la historia colombiana. En: Arellano, Ángel (coord.). 
El triunfo de las campañas posmodernas. Los casos de las alcaldías de Bogotá y Medellín...

Nuevas campañas electorales en América Latina (pp. 13-21). Montevideo: KonradAdenauer Stifung.

44. Petro, Gustavo [petrogustavo]. (2018, 27 octubre). En Bogotá gana Claudia López. No nos representa. El movimiento Colombia Humana será independiente a su gobierno. Felicito a Morris por mantener vivas las banderas de la Bogotá Humana, pero ya Bogotá decidió destruir el proyecto del metro subterráneo para la ciudad. [Tuit]. Recuperado de https://twitter.com/petrogustavo/status/1188585008027578370

45. Piedra Guillén, Nancy. (2003). Feminismo y postmodernidad: entre el ser para sí o el ser para los otros. Revista de Ciencias Sociales, Iv (102), pp. 43-55.

46. Quintero Calle, Daniel [QuinteroCalle]. (2019, 7 de septiembre). Les dije que se vendría la política cochina de montajes y ataques. Ellos son así. Seguiremos caminando a Medellín, en foros y debates. Uniendo a Medellín en torno a los valores que nos enseñaron los abuelos... [Tuit]. Recuperado de https://twitter.com/ QuinteroCalle/status/1170475439514669056

47. Quintero Calle, Daniel. (2019, 15 de octubre). Nuestra campaña se ha hecho con la gente, no tenemos jefes ni estamos aliados con partidos políticos que quieran venir a decirnos cómo gobernar. [Tuit. Recuperado de https://twitter.com/ QuinteroCalle/status/1184157922336694276

48. Quintero Calle, Daniel. (2019, octubre 21). Somos La Nueva Política. Daniel Quintero Calle. Alcalde de Medellín. [Archivo de video]. Recuperado de https://www. youtube.com/watch?v=9k-1BCHjBOM

49. Rahat, Gideon \& Kenig, Ofer. (2018). From party politics to Personalized Politics. Party Change and Political Personalization in Democracies. Oxford: Oxford University. https://doi.org/10.1093/oso/9780198808008.001.0001

50. Registraduría Nacional del Estado Civil. (s. f.). Consulta documentos escrutinio elección autoridades territoriales 2019. Recuperado de https://elecciones2019. registraduria.gov.co/

51. Rico Camps, Guillem. (2002). Candidatos y electores: la popularidad de los líderes políticos y su impacto en el comportamiento electoral. Barcelona: ICPS.

52. Rincón, Omar. (2011). Mucho ciberactivismo... pocos votos. Antanas Mockus y el Partido Verde colombiano. Nueva Sociedad, 235, pp. 74-89.

53. Salmon, Christian. (2007). Storytelling: la máquina de fabricar historias y formatear las mentes. Barcelona: Península.

54. Sánchez Galicia, Javier. (2010). Treinta claves para entender el poder. Léxico para la nueva comunicación política. México, D. F.: Piso 15.

55. Sánchez Medero, Rubén. (2009). La comunicación política española, ¿un modelo propio o una adaptación del modelo estadounidense? Revista de Ciencias Sociales, 15 (1), pp. 9-23.

56. Sartori, Giovanni. (1976). Partidos y sistemas de partidos. Madrid: Alianza. 
57. Semana. (2016, julio 26). Daniel Quintero: del Partido del Tomate a viceministerio en MinTIC. Recuperado de https://www.semana.com/tecnologia/ articulo/daniel-quintero-del-partido-del-tomate-a-viceministerio-en-mintic/483471

58. Semana. (2019, septiembre 12). «No soy ni el candidato de Uribe, ni el de Petro, ni el de Fajardo»: Daniel Quintero. Entrevista a Daniel Quintero candidato a la Alcaldía de Medellín. Recuperado de https://www.semana.com/nacion/articulo/ entrevista-a-daniel-quintero-candidato-a-la-alcaldia-de-medellin/631492

59. Semana. (2019, noviembre 4). La nueva Claudia. Recuperado de https://www. semana.com/nacion/articulo/claudia-lopez-como-alcaldesa-de-bogota-ha-cambiadosu-tono/638871

60 Tamayo Ortiz, Heidi. (2019, octubre 27). Esto hará Daniel Quintero si se convierte en alcalde de Medellín. El Tiempo. Recuperado de https://www.eltiempo. com/elecciones-colombia-2019/medellin/daniel-quintero-candidato-a-la-alcaldia-demedellin-habla-de-sus-propuestas-424184

61. Telemedellín. (2020, enero 1.o.). Este es el Valle del Software que Daniel Quintero quiere consolidar en Medellín-Telemedellín. Recuperado de https://www. youtube.com/watch? $\mathrm{v}=$ MoN2a89doEw

62. Telesur. (2019, octubre 26). ¿Cuál es el rol del proceso de paz en las elecciones regionales en Colombia? Recuperado de https:/www.telesurtv.net/news/colombiaelecciones-regionales-proceso-paz-violencia-20191023-0010.html

63. Torrado, Santiago. (2019, octubre 25). Claudia López, la mujer que enfrentó

[278] la corrupción quiere gobernar Bogotá. El País. Recuperado de https://elpais.com/ internacional/2019/10/24/colombia/1571884054_826101.html

64. Trout, Jack y Rivkin, Steve. (1996). El nuevo posicionamiento. México, D. F.: McGraw-Hill.

65. Valdez Zepeda, Andrés. (2010). Las campañas electorales en la nueva sociedad de la información y el conocimiento. Estudios Políticos (México), 20, pp. 155-165. https://doi.org/10.22201/fcpys.24484903e.2010.20.24279 